\title{
Atenção Primária: Rodas de Conversa com a Comunidade na Prevenção da Obesidade Infantil no Município de Alegrete, Rs.
}

\author{
Truccolo, Adriana Barni; Salbego, Maria do Horto; Tubino, Adelina \\ Universidade Estadual do Rio Grande do Sul — truccoloab@hotmail.com
}

Introdução: a atenção primária é a porta de entrada do usuário no sistema público de saúde e em parceria com as escolas torna-se uma potente ferramenta na disseminação da cultura da alimentação saudável. As rodas de conversa aproximam a comunidade para uma reflexão, possibilitando a abertura de espaços de encontro, de escuta, de troca e compartilhamento de experiências auxiliando a novas práticas e escolhas saudáveis e tornando a família um sistema de apoio às crianças. Objetivo: o projeto de extensão "Rodas de Conversa na Atenção Primária" teve por objetivo a sensibilização da comunidade na questão da obesidade infantil, visando aperfeiçoar ações voltadas para a resolução de problemas relacionados à doença. Métodos: a metodologia utilizada foi as rodas de conversa com a comunidade em sete Estratégias da Saúde da Família (ESF) do município de Alegrete, com duração máxima de duas horas, enfatizando a mudança e a incorporação de hábitos saudáveis e a promoção, de forma competente, do acesso à informação, respeitando a cultura dos indivíduos e de seu grupo social. Os atores desse processo foram as Secretarias da Saúde, Educação e Cultura e Assistência Social do município de Alegrete bem como discentes e docentes da Universidade, lideranças comunitárias, mobilizados e articulados com a proposta de intervenção na comunidade para a promoção e incorporação de hábitos de vida saudáveis às famílias. Resultados: Este projeto constituiu uma grande rede que entrelaçou ações, atores sociais, comunidade, ambiente escolar em torno da questão da obesidade infantil, atuando como espaço de acolhimento, de escuta e de superação de problemas que são comuns às crianças. Dessa forma resultou no aumento do conhecimento sobre os problemas decorrentes do excesso de peso e obesidade infantil por parte das famílias que são espelhos para seus filhos, para a conscientização das crianças da importância da manutenção de hábitos de vida saudáveis como alimentação e práticas corporais. Conclusão: Humanizar é incluir a diversidade, o conflito. Assim, nas rodas de conversa que exercitamos, procuramos promover a circulação da palavra para que todos tivessem a possibilidade de falar. Observamos que a cada encontro e em cada intervenção, por menor que ela que fosse, houve a possibilidade de mudança. por fim, levando em consideração que os pais influenciam constantemente o relacionamento de seus filhos com os alimentos e são um modelo em suas atitudes, em seus hábitos alimentares e em suas atividades físicas, a atenção primária, atuou efetivamente como espaço promotor de saúde sendo o cenário de rodas de conversa e sensibilização sobre o tema obesidade infantil.

Truccolo, Adriana Barni; Salbego, Maria do Horto; Tubino, Adelina. Atenção Primária: Rodas de Conversa com a Comunidade na Prevenção da Obesidade Infantil no Município de Alegrete, Rs.. In: Anais do

Congresso Internacional de Humanidades \& Humanização em Saúde [= Blucher Medical Proceedings, num.2, vol.1]. São Paulo: Editora Blucher, 2014. ISSN 2357-7282

DOI 10.5151/medpro-cihhs-10445 